\title{
DATA ON THE SPECTRAL ERYTHEMIC REACTION OF THE UNTANNED HUMAN SKIN TO ULTRAVIOLET RADIATION
}

\author{
By W. W. Coblentz and R. Stair
}

\section{ABSTRACT}

This paper gives a revision and an extension in spectral range of the data, previously published ${ }^{1}$ on the spectral erythemic reaction of the untanned skin.

The erythemic reaction is a convenient and accurate indicator of the tolerance of the human skin to ultraviolet radiation. Hence, before irradiating large areas, a preliminary exposure should be made on a small area to determine the time to produce a minimum perceptible erythema, thus avoiding burns.

A knowledge of the spectral erythemic response is, therefore, of importance in evaluating the ultraviolet output of a lamp. By means of data on the spectral erythemic reaction on the skin and a simple physical measurement ${ }^{2}$ of the radiant flux emitted by the lamp, it is possible to calculate the approximate time of exposure that may be made without causing severe burns on the average pigmented skin.

In a previous communication ${ }^{3}$ data were given on the spectral erythemic response of the untanned human skin to ultraviolet radiation, in the wave length range extending from 2482 to $3130 \mathrm{~A}$.

In the meantime Rüttenauer ${ }^{4}$ presented data on the erythemic response to filtered radiation of wave length $3261 \mathrm{~A}$, which he obtained from a low-pressure cadmium arc lamp. He found that the spectral erythemic response at $3261 \mathrm{~A}$ is 0.003 to 0.004 that of the emission line at $2967 \mathrm{~A}$; and that this erythema has the property of changing rapidly into pigmentation. The color of the erythema and of the pigmentation is similar to that produced by sunlight.

Experiments seem to indicate that, in the spectral range where these two reactions are produced, the longer the wave length the greater appears to be the pigmentation ${ }^{5}$ relative to the erythemic reaction. Furthermore, since, for the long wave lengths, pigmentation begins before the erythema has disappeared (also there is a

\footnotetext{
1 Coblentz, Stair, and Hogue, B.S.Jour. Research, vol. 8 (RP433), p. 541, 1932.

2 Tests of a Balanced Thermopile and Filter Radiometer as a Standard Ultraviolet Dosage Intensity Meter, W. W. Coblentz, R. Stair, and J. M. Hogue, B.S.Jour. Research, vol. 8 (RP450), p. 759, 1932. Also see Acceptance of Sun Lamps, by the Council on Physical Therapy, Jour. Am. Med. Association, vol. 100, p. 1863, June 10,1933.

3 See footnote 1 .

1 Rüttenauer, Proc. IIe Congrès International de la Lumière, Copenhagen, p. 72, Aug. 18, 1932, published by Engelsen and Schroeder, Copenhagen.

5 Uhlmann, Strahlentherapie, 35, p. 361, 1930; also papers by Gutman (cited by Uhlmann), and by Hausser and Vahle, etc., cited in our previous publication, reference 1.
} 
similarity in color of the skin for these two reactions) there is difficulty in deciding when the erythema has completely disappeared.

Because of the rapid formation of pigment (tanning) after exposure to the emission line at $3130 \mathrm{~A}$, the writers experienced difficulty in deciding when the erythema had completely disappeared. As a consequence, there was a possibility of overestimating the magnitude of the erythemal reaction.

It is possible that Rüttenauer may have experienced a similar difficulty. Nevertheless, in spite of the smallness of the erythemal reaction measured, Rüttenauer's data are useful in establishing the long wage-length limit of spectral erythemic reaction. Accepting his values, as given, the writers have extended their curve of spectral erythemic reaction to wave lengths longer than $3150 \mathrm{~A}$, previously published. Furthermore, to meet the needs for higher accuracy, they have made a further study of, and have revised, the previously published data, all of which are given in table 1 . The new data in the spectral range of 3150 to $3300 \mathrm{~A}$ have but little effect upon the evaluation of the erythemogenic efficiency of therapeutic lamps, given in previous papers.

\section{TABLE 1}

The relative spectral erythemic response of the untanned human skin, of average pigmentation, to equal amounts of radiant energy, based upon the measurements of Hausser and Vahle (spectrally homogeneous radiation, 1922 and 1927); of Luckiesh, Holladay and Taylor (filter method, 1930); of Coblentz, Stair, and Hogue, using (in 1931) spectrally homogeneous radiation, and (in 1932) heterogeneous radiation from a "cold quartz" mercury vapor lamp, having 98 percent of the erythemogenic radiation in the emission line at $2537 \mathrm{~A}$; and of Rüttenauer (IIe Internat. Congrès de la Lumière, Copenhagen, 1932) using the filtered cadmium line at $3261 \mathrm{~A}$. The asterisk (*) indicates emission lines of the mercury arc.

\begin{tabular}{|c|c|c|c|}
\hline Wave length (angstroms) & $\begin{array}{l}\text { Erythe- } \\
\text { mic re- } \\
\text { sponse }\end{array}$ & Wave length (angstroms) & $\begin{array}{l}\text { Erythe- } \\
\text { mic re- } \\
\text { sponse }\end{array}$ \\
\hline $\begin{array}{l}2,400 \\
2,446^{*} \\
2,482^{*} \\
2,500 \\
2,537^{*} \\
2,676^{*} \\
2,650^{*} \\
2,675^{*} \\
2,700^{*} \\
2,753^{*} \\
2,804^{*} \\
2,850 \\
2,857^{*}\end{array}$ & $\begin{array}{l}0.56 \\
.57 \\
.57 \\
.57 \\
.55 \\
.49 \\
.42 \\
.25 \\
.20 \\
.14 \\
.07 \\
.06 \\
.09 \\
.10\end{array}$ & $\begin{array}{l}2,894^{*} \\
2,900 \\
2,925^{*} \\
2,950 \\
3,967^{*} \\
3,000 \\
3,022^{*} \\
3,1000 \\
3,130 * 2 \\
3,150 \\
3,200 \\
3,25000\end{array}$ & $\begin{array}{r}0.25 \\
.31 \\
.70 \\
.98 \\
1.00 \\
.83 \\
.55 \\
.33 \\
.11 \\
.03 \\
.01 \\
.005 \\
.003 \\
.000\end{array}$ \\
\hline
\end{tabular}

Washington, September 30, 1933. 